\title{
Supported housing and housing support for the psychiatrically disabled - Background, population, policies, practices and current challenges
}

\author{
David Brunt E Lena Tibblin
}

David Brunt, RN, PhD, is an Associate Professor, Director of Postgraduate Studies, Linnaeus University. Lena Tibblin, Social Worker, is a Care Assessment Officer, Municipality of Växjö.

\begin{abstract}
This article presents an overview of the development of supported housing and housing support for the psychiatrically disabled in Sweden as well as a short résumé of the major policies, reforms and agencies that have influenced this development, in particular the Mental Health Care reform of 1995 and the National Agency for the Co-ordination of Psychiatric Services. Characteristics of the residents and residences are described. The specific role of the care assessment officer in the light of three case examples is discussed and the current challenges facing the providers of housing and support for the psychiatrically disabled in Sweden are presented.
\end{abstract}

\section{History of social policy and reforms concerning housing for the psychiatrically disabled in Sweden}

The following historical background reviews the housing issue for this target group and covers both the relevant international trends, common for most Western countries, as well as the specific features of this field in Sweden. From the mid 19th century to about 1960 the major locus of care and housing for psychiatric patients was the mental hospital. This type of institution was developed in strikingly similar ways in the Western world (Hansson, 1993). The notion that schizophrenia was an incurable condition meant that hospital treatment was often life-long for many patients. The primary aims of the mental hospital or asylum were to contain as well as treat patients. Hospitals offered the basic necessities for survival to people with a wide range of clinical and social abnormalities and were often situated remote from population centres. The choice of sites fitted the need to remove the perceived threat to the public safety from persons with a mental illness and was consistent with then current views of mental hygiene, which held that recovery was facilitated by restful country settings.

The process of deinstitutionalisation began in the 1960s and was prompted mainly by three considerations: clinical, influenced by the arrival and widespread use of an anti-psychotic agent, chlorpromazine; humanitarian/ideological, where negative effects of institutional 
life were highlighted (Goffman, 1961); and financial, concerns to reduce high maintenance costs for large institutions with large staff populations (Scull, 1984). A major feature of the process of deinstitutionalisation was the drastic reduction of custodial care and an exodus of patients from long-stay wards. This was followed by a corresponding increase of nonhospital residential facilities, including both congregate and independent solutions. For Sweden the reduction was from 35,000 to 5,000 admitted patients over a 30-year period (Grunewald, 1997).

From an international perspective housing for the psychiatrically disabled has evolved through three main phases. The first, as stated above, was that of institutionalisation with often life-long residency for patients once they had been admitted. The advent of deinstitutionalisation denoted the second phase with two discernible dominant features: the treatment orientation of the large-scale residential facilities and their inherent temporary and transitional nature with the development of a residential continuum. The latter inferred that a person achieved a certain level of functioning in one setting and moved to a higher level to further improve functioning in less structured environments (Middelboe, 1995). The third and current phase of the development of residential facilities, which began in the early 1990s, denoted a paradigm shift from the linear approach as above to the establishment of a supported housing model, entailing small-scale solutions. The temporary and transitional nature was replaced by permanent housing solutions. A proliferation of housing models has since been developed where congregate supported housing or small group homes have better met the declared preferences of persons with a severe mental illness (Middelboe, 1995).

Large-scale transitional, treatment-orientated residential facilities, as seen in the second phase above, were never developed in Sweden, although existing nursing homes admitted some of those patients discharged from mental hospitals who were deemed not able to cope in community based housing. The gradual reduction in the number of hospital beds and the discharge of patients was more closely tied to the organisational changes of the 1970s and 1980s where community and inpatient psychiatric services began to be administered in geographical sectors in accordance with the principal catchment area. A study by Forsberg and Starrin (1993), of 223 discharged patients showed that 43\% had moved to their own accommodation, $30 \%$ to old people's homes, $24 \%$ to a somatic nursing home and $3 \%$ to group accommodation.

In the Swedish context of housing for persons with severe mental illness, which has mostly evolved during the 1990s, there are three main levels of supported housing. The first level includes the privately run group homes/nursing homes often occupied by elderly or disturbed patients referred there by the local authority social services unable to provide suitable local accommodation and services. The second level includes the municipality-run supported housing, for example, group homes. The latter that were brought into use in the 1980s in Sweden had residents sharing a house or large apartment. This form of residential facility is generally being phased out in favour of self-contained apartments that are grouped together with a staffed communal area in the same building. The range of staff supervision can vary from office hours only to permanent night staffing depending on the residents' needs. The third level is independent living with specialised housing support. 


\section{Legislation, social policy and reforms}

In 1990 the Swedish government instructed a Parliamentary Commission to consider and suggest measures concerning the care of persons suffering from mental illness. The Commission's remit also covered a number of particular aspects of the life conditions of the target group, including housing alternatives. The Commission maintained that the housing issue was the single factor that had the greatest influence on the living conditions of persons with mental illness. An inventory showed that half of the total number of patients admitted for psychiatric care had no accommodation of their own. The Commission also stated that the municipal social services had not sufficiently attended to the target group's needs of housing and housing support. A lack of clarification in the division of responsibilities between the municipal social services and the county health authorities was seen to have contributed to this state of affairs and the co-ordination of services and collaboration between these two major actors in the field was considered to be insufficient (SOU, 1992).

An essential part of the resulting reform, the Mental Health Care reform, that took effect in 1995, was the Municipal Financial Responsibility Act. This act made it incumbent upon the municipalities to pay for the care of inpatients who, after three consecutive months of treatment, had been deemed by a psychiatrist as fully medically treated within the psychiatric inpatient system, but were still being cared for in hospital. One of the major aims of this act was to stimulate the development of new forms of housing for persons with severe mental illness who had been under long-term institutional care, as well as to stimulate better coordination of services for persons with severe mental illness by the health authorities and the social services. This act was complemented by state subsidies to ease the transition from life in an institution to living in the community (National Board of Health and Welfare, 1999).

The guiding principles of the Commission's proposals to the Swedish government were:

- Persons with a psychiatric disability are to have the same rights and obligations as others in society.

- A person with a psychiatric disability has the right to service, support and care suited to his/her individual needs.

- The person's own choice and priorities are to form the basis for all services focused on that person.

- Service, support and care is to be provided in as open and normalised forms as possible in the local community where the persons live.

- Services are to be provided in such a way as to give support to the individual's independence and integrity.

- Services are to be provided in such a way as to give support to the individual's welfare.

According to the official evaluation of the reform in 1999, 30\% of the residential alternatives for persons with severe mental illness had existed prior to the reform, $30 \%$ had been transferred from the health authorities to the social services and $40 \%$ had been established after the Mental Health reform. The evaluation report also stated that it was often the existing resources that decided which type of residential alternative was offered to persons suffering from mental illness. Furthermore it was found that the supply could depend on a 
municipality's ideological view on what constitutes a good residential solution, independent living or congregate living (National Board of Health and Welfare, 1999).

The drop in numbers of hospital beds for psychiatric patients and transferences of patients due to the reform, especially those with long-term disorders, was met by an increase in housing alternatives provided by social services. This is clearly shown in Table one where 24-hour care services provided by the social services have overtaken those of the psychiatric services.

Table one. Number of people with mental disorders in 24-hour care provided by psychiatric care and social services in 1994, 1997 and 2002. (Source: the National Board of Health and Welfare).

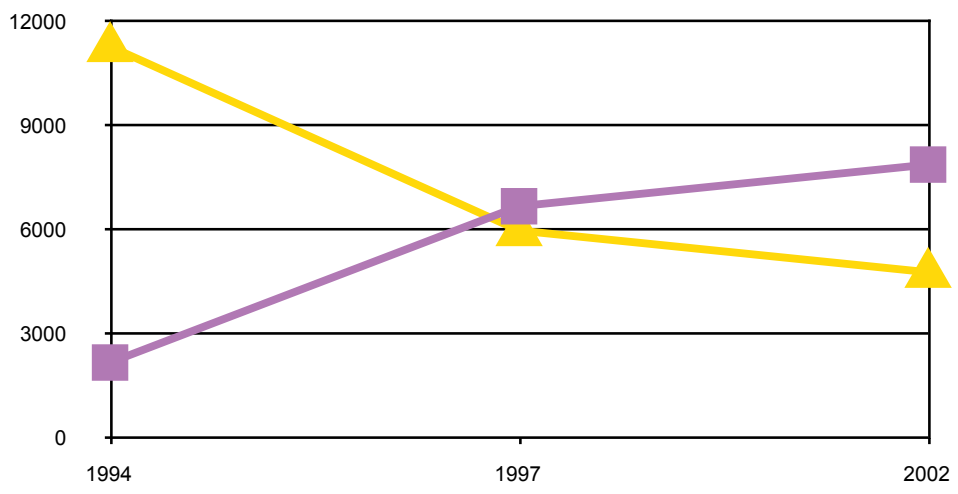

Social Services

Psychiatry

\section{The population served and the residential units}

It is important here to define the nomenclature used in the housing field. Supported housing refers to an organised housing situation where two or more people live together or in selfcontained apartments grouped together with staff available close by. Congregate housing, group homes and staffed residential units, are examples of supported housing. Housing support refers to independent living where the individual receives help and support in his / her home on a regular basis.

The prevalence of mental disorder in Sweden is equal to that of many European countries. In a recent survey of functional impairments there were 150,000 people with psychiatric disorders in Sweden out of a total population of 9.3 million (approx.) (National Board of Health and Welfare, 2006). Of the 150,000 diagnosed as having a mental disorder approximately 43,000 are judged to be those in need of care from the county health authorities' psychiatric care organisations as well as the municipalities' social services. A larger concentration of this group can be found in the three major cities: Stockholm, Gothenburg and Malmö. Ninetysix persons per 10,000 of the population from these cities were from this group while the 
corresponding figure for the rest of the country was 56. A major problem is that a number of the target group live in supported housing far from the town where they are registered. This is particularly the case for individuals from the three major cities.

A survey carried out in 2008 by the National Board of Health and Welfare, showed that approximately 8,000 persons from the target group lived in supported housing in Sweden. Three quarters of these were in the public sector as part of the municipalities' supported housing programmes and one quarter were in the private sector run by entrepreneurs but commissioned by the municipalities. No reliable statistics are available for the municipalityrun housing support programmes where individuals receive support and services in their own accommodation but a reasonable assumption is that 20-25,000 people with a long-term mental illness receive this type of housing support.

\section{The residents}

The following demographics and other statistics about residents and their residences refer to the survey of supported housing programmes by the National Board of Health and Social Welfare (2003). The distribution of sex and age of those residing in the housing support programmes is presented in Table two. There is a majority of men (60\%) while more than half are in the age bracket 31-55 years of age, the women are more evenly distributed over the age groups and a greater proportion of women are $>65$ years of age. The vast majority of these individuals live alone as the survey of their family situation showed that only $3.6 \%$ were married or cohabiting and only $6.5 \%$ had children under 18 years of age living at home with them. Ten percent of this group were born abroad and the most commonly occurring diagnosis was schizophrenia (Table three).

Table two. Distribution of sex and age among persons with a psychiatric disability in supported housing programmes in Sweden $(\mathrm{N}=6610)$.

\begin{tabular}{lrrrr} 
Age groups & \multicolumn{2}{c}{ Men } & \multicolumn{2}{c}{ Women } \\
& $\mathbf{N}$ & $\%$ & $\mathbf{N}$ & $\%$ \\
$<17$ & 84 & 2 & 53 & 2 \\
$18-30$ & 351 & 9 & 244 & 9 \\
$31-45$ & 1,189 & 30 & 592 & 23 \\
$46-55$ & 989 & 25 & 537 & 20 \\
$56-64$ & 618 & 16 & 416 & 16 \\
$65-74$ & 409 & 10 & 342 & 13 \\
$74-$ & 333 & 8 & 453 & 17 \\
Total & 3,973 & 100 & 2,637 & 100
\end{tabular}

\section{The residences}

The size of the residential alternatives in the survey varied from two persons to 125 . In the case of the latter the residents lived in several smaller residential units. The average number of residents in these residential units was 12 . Approximately $47 \%$ lived in units where more than 15 people lived. A noticeable difference is that the supported housing units run by the municipalities were often smaller with greater levels of independence within a congregate framework than the privately run residential units which in many cases were housed in 
premises previously utilised as nursing homes for the long-term mentally ill. Another consequence for those living in privately run supported housing residences was that a far greater proportion had to share a room and/or bathroom with someone else, in contrast to the experiences of those in the municipality run residences. The average staffing levels including all categories except administrative staff were approximately 0.8 per resident.

Table three. Distribution of psychiatric diagnoses among persons in supported housing programmes in Sweden (excluding those where no diagnosis was available) $(\mathrm{N}=5842)$.

\section{Diagnosis}

Schizophrenia

Other psychosis

Personality disorder (incl neurosis/anxiety)

Learning disability and dementia

Neuropsychiatric conditions

Alcohol and drug abuse

Other diagnosis

Total

$\begin{array}{rr}\mathbf{N} & \% \\ 3,340 & 57 \\ 1,019 & 18 \\ 490 & 8 \\ 501 & 9 \\ 245 & 4 \\ 164 & 3 \\ 83 & 1 \\ 5,842 & 100\end{array}$

Finally an interesting section of the survey was the focus on 'institutional' and 'homelike' characteristics, giving an important indication of the extent to which community based supported housing offered a more home-like and less institutional atmosphere than the institutions they replaced. These characteristics are presented in Tables four and five; the most salient features are that many of the residences have some form of institutional characteristics in terms of size and the sharing of rooms and / or bathrooms. Once again it is the privately run residences that have a greater proportion of these institutional characteristics. The authors of the survey report conclude by surmising that these figures indicate that one group $(2,681$ persons, $41 \%$ ) live in supported housing with what the Mental Health Care reform aimed to achieve, i.e. housing in more home-like conditions. A second group live in conditions more associated with an institution (2,125 persons, 32\%), while a third group (1,810 persons, 27\%) live in supported housing that does not belong to either of these two extremes.

Table four. Distribution of number and percentage of persons for variables that can be associated with a unit's level of 'institutional' characteristics ( $\mathrm{N}=6700$ approx.).

\section{Institutional characteristics}

1. The residential unit has 15 places or more

2. Sharing room and/or bathroom

3. Not able to come and go as one pleases, not having one's own key or guests in one's room without permission

4. No rehabilitation measures

Combinations of the above

$1+2$

$1+2+3$

$1+2+3+4$

At least three of 1 - 4

\section{Number $\%$ of group}

$3,219 \quad 49$

$4,571 \quad 69$

$2,513 \quad 38$

$2,711 \quad 41$

$2,626 \quad 40$

$1,357 \quad 21$

$388 \quad 6$

$2,125 \quad 32$ 
Table five. Distribution of number and percentage of persons for variables that can be associated with a unit's level of 'home-like' characteristics ( $\mathrm{N}=6700$ approx.).

Home-like characteristics

1. The residential unit has a maximum of 10 places

2. Own room with one's own furniture (if desired)

3. Able to come and go as one pleases, having one's own key and allowed to have guests in one's room without permission

4. Living in the municipality where one is registered

Combinations of the above

$1+2$

$1+2+3$

$1+2+3+4$

At least three of 1 - 4
Number $\%$ of group

2,567

4,203

39

4,009

3,585

61

54

2,066

31

1,525

1,346

2,681
23

20

41

\section{Agencies and authorities responsible for policies and practices}

The Swedish health care and social services system is supported and governed at three political levels - central government, the counties and the municipalities. Central government is responsible for legislation within the health care system and the health insurance system. This includes disability pensions for people with long-term psychiatric illness, as well as general and directed subsidies to counties and municipalities to help them implement various public service measures. The National Board of Health and Welfare is the Swedish national expert and supervisory authority for the social services and health services. Amongst its duties are the following:

- Issuing provisions and general advice in its Code of Statutes,

- Publishing guidelines for care and treatment,

- Being responsible for co-ordination and development of supervision in the social services together with the county administrative boards, and

- Following up and evaluating reforms, legislation and activities conducted by municipalities and county health authorities.

The county councils (21 in total) are responsible for operating specialised health care services for people with psychiatric or somatic illness. This includes hospitals and primary health care services. The municipalities (290 in total) are responsible for social services for the elderly and disabled, including people with psychiatric disorders. These services include social support, rehabilitation measures, medical care and housing. The objectives for their activities are laid down in the Social Services Act 2001 (SFS 2001:453): the social services shall seek to 'liberate and develop the resources of the individual and the group', while account shall be taken of each person's responsibility for their own social situation and that of others. This Act also states that 'measures intended for the individual shall be designed and implemented jointly with him or her'.

\section{National agency for the co-ordination of psychiatric services}

A number of tragic and violent incidents occurred in 2003 in Sweden, including the murder of the then Swedish Foreign Minister. The common denominator for these incidents was 
that the perpetrators were persons suffering from mental disorders and it was judged that deficiencies in the care and treatment of persons with severe mental illness was a major contributory factor. It was at the same time an indication that the changes instigated by the Mental Health Care reform of the mid 1990s had not been successful. The Swedish government responded by creating a national agency for co-ordinating psychiatric services. The remit for the agency included 17 major areas to be investigated and recommendations to be made concerning the county authorities' psychiatric health care and the municipalities' services for the target group. Where housing was concerned, the remit stated simply that there was a need to analyse how the social services' housing support programmes could be developed and improved. A comprehensive research and development programme, led by the first author, began in 2005, focusing on supported housing and housing support for persons with a psychiatric disability and 18 reports (of 24) have so far been published. The first author is currently employed by the National Board of Health and Welfare to lead a programme to create guidelines and recommendations for the municipalities' provision of housing services for the target group. The national agency maintains that housing services for this group should be based on three major principles: normalisation, being able to live as others in the community; freedom of choice, independent living if desired, participating in the choice of accommodation and its furnishing; and needs, where support is to be provided on the basis of meeting individual needs.

\section{Practices - housing support and the assessment of needs}

A hospital for patients suffering from mental illness has been in existence in the county of Kronoberg since the 1500s, although there are now less than 100 beds in the psychiatric clinic that serves the whole of the county. In the following discussion, examples from the social services department of the Växjö municipality are provided. Växjö, located in southern Sweden, has a population of 80,000 (approx.). In 1998 an inventory showed there were 800 people in Växjö with a long-term mental illness. In September 2006, 145 persons received housing support in their own apartments and 93 in supported housing. The growth of housing support has superseded the need for supported housing with low levels of staffing, while the need for supported housing with 24-hour support still remains.

Persons with a psychiatric disability are given support in their daily life in accordance with two pieces of legislation: The Social Services Act 2001 (SFS 2001:453) and the Act concerning Support and Service for People with Certain Functional Impairments 1993 (Disability Act SFS 1993:387). The former contains regulations regarding a person's right to financial and social assistance and in terms of housing for persons with a psychiatric disability; this can mean specially adapted apartments, group accommodation, home help services or housing support. The Social Services Act 2001 (SFS 2001:453) can be seen as the basic legislation in the social field, intended to provide services for a period in an individual's life. As a citizen one is guaranteed a reasonable standard of living through the measures one receives. A person's application for services is individually assessed and what is considered a reasonable standard of living may differ between different persons depending on age, habits etc and what is a reasonable standard of living for other persons in that age group.

The Disability Act 1993 (SFS 1993:387) is intended for those with the most severe disabilities, physical or psychiatric, where the problems are seen as being life-long. In order to be eligible to receive the help and support available in accordance with this Act one has 
to both belong to one of the target groups and be in need of one or more of the 10 specified measures that are clearly defined. With this assistance one is guaranteed a good standard of living.

The most common measures for persons with a psychiatric disability, regardless of which legislation is used, are different kinds of supported housing and housing support. Housing support is similar to the home-help services provided for the elderly but has a more pronounced rehabilitative content and has the aim of attaining a greater level of independence for the individual. The assistants work together with the person in need of support. Housing support may consist of the following:

- Support to increase motivation and the ability for the individual to take more responsibility for his/her situation and home

- Support to find and maintain routines for everyday life

- Possibilities of being together with others

- Support to prevent social isolation and to promote participation in daily activities outside the home

- Support to meet friends and relatives and to increase one's social network.

In order to receive housing support or a place in a supported housing programme an application has to be made to the social services which is followed by an investigation of the individual's needs by a care assessment officer. It is not unusual that the application is preceded by meetings between the person in need of support and the care assessment officer in order to inform the person about the support and motivate the individual with a psychiatric disability to receive support. This can sometimes be a dilemma for the care assessment officer, observing the needs and feeling a responsibility to help this person but at the same time respecting the right of self-determination. Persons with a long-term mental illness can often lack an insight into their illness and its consequences for life in the community and the two parties can present different views of what type of and how much support and help is needed. There is a delicate balance between informing an applicant of his / her rights, motivating the individual to receive assistance and misusing one's influence as a person in authority. The investigation by the care assessment officer contains a description of the applicant's need for support as described by the person him/herself and, if the applicant has given consent also from other professionals who know the person, such as a doctor, nurse, social worker or occupational therapist.

The investigation is followed by a decision, positive or negative, where the application is assessed on the basis of the legislation. The decision is often positive. The most important part of the assessment process, and maybe the most difficult, is to stay focused on the will of the client and try to find a good way to support this person. Opinions about what type of support is most appropriate may also differ between the professionals who are in touch with the client.

Issues raised by clients about housing support often concern the cost of the support. The municipalities have the right to determine whether to charge fees for housing support or not. There are great differences between the municipalities and the fees vary from nothing to the maximum allowed charge for home help services (SEK 1500month approx.). One of the common consequences of a long-term mental illness is a poor financial situation, 
mostly due to a low disability pension that is based on previous earnings. Many of the target group have not been able to work gainfully for any length of time thus leading to small disability pensions. This fact combined with a lack of insight into one's total needs of support can result in the individual not wanting to receive support if there is a charge. The need to pay for something that one did not want in the first place can of course lead to motivation problems and the individual not wanting or receiving help that those around him/ her see is necessary. Another issue often raised is the importance of predictability. The individual wants to know when the assistant will be coming and who it is that is coming to help. The relationship created between the individual and the assistant supporting that person is probably the most important aspect of that support and continuity among the staff is of great importance.

In the following there are some examples of housing support for persons with a psychiatric disability:

Case Example 1: A young woman has recently moved to her first apartment where she lives alone. She has an eating disorder and suffers from anxiety especially when it comes to activities around the meals; preparing the meals and eating them. Even though needing support in some activities she is quite self-sufficient in others. She has, for example, no problem in keeping her apartment clean or caring for her laundry. To attain a good everyday life she needs support to find routines around all the daily chores and she needs help to participate in activities outside her apartment. The support is focused on the meals in order to create routines which work even when she is alone. It is also important for her to have time to plan the coming week and evaluate how the past week has been.

Case Example 2: A 45-year old man who suffers from schizophrenia. Medication is of great importance for this man and his possibilities of living a life with some degree of independence and self-sufficiency. An important part of the support given to him is motivating him to take his medication on every prescribed occasion. His current symptoms and the consequences of long-term mental illness have contributed to his difficulties in such a way that he is often apathetic and lacks the initiative to undertake even the simplest of household tasks, for example, around mealtimes and personal hygiene. This man thus has a great need of help in order to initiate, carry out and complete these duties as well as activities outside his home. The support is provided on a daily basis.

Case Example 3: A 30-year old man with a diagnosis of autism, but without any intellectual disability. The diagnosis that has recently been made entitles him to support in accordance with the Disability Act 1993 (SFS 1993:387). The man receives housing support twice a week that focuses on taking care of his home and doing the shopping. The new knowledge, emanating from the new diagnosis, and the investigation that has been carried out dictate that the support has to be formulated in a different way than previously, with a more educational approach to the support given. The main focus in the support for this man is to help him plan his everyday life and provide a structure and predictability in his life.

\section{Current challenges}

In a study of the homeless by the National Board of Health and Welfare (2006) it was found that 17,800 people in Sweden did not have their own accommodation. This represented $0.2 \%$ 
of the population and about 900 persons slept on the streets. Approximately $40 \%$ of those without accommodation had a mental health problem, a figure which has risen in recent years. This represents a serious challenge to the social services.

Measures to make it possible for persons with a psychiatric disability to live in the community in Sweden have developed over the past 20 years. Supported housing and housing support has been provided and many from the target group live a far better life than previously; there is however still much to be done. The Mental Health Care reform and the plans to improve services by the new national agency have mainly been focused on the large group of people with a psychosis diagnosis. New groups of individuals presenting different needs that require a different approach are currently challenging the municipal housing support teams, who have just learned to cope with and attend to the needs of the type of person in Case 2 above but now have to also meet the varying needs presented by people similar to Cases 1 and 3. In Växjö a supported housing programme for persons with a neuropsychiatric disability (as in Case 3 ) has started.

The municipalities, and in particular the larger cities, have not been able to provide supported housing for all who need it and have been forced to use private residential alternatives often far from the individual's home town. The private alternatives as shown above more often have more institutional characteristics in terms of size, shared space and restrictions in freedom of movement. The challenge is to fulfil the originally stated aim of the government to provide housing in a home-like environment in the community close to one's home town.

Furthermore care assessment officers who investigate the needs of this target group for housing support face a dilemma. On the one hand there are demands for greater user participation and freedom of choice for the individual in the provision of services as well as statutory legal provisions. On the other hand the care assessment officer is constrained by a stretched municipal budget, suffering from expansive central government promises and insufficient central government subsidies to meet these promises.

\section{Authors' contact details}

David Brunt, School of Health Sciences and Social Work, Linneaus University, Georg Lückligs väg 8, S-351 95 Växjö, Sweden. E-mail: david.brunt@lnu.se

Lena Tibblin, Växjö kommun, Box 1222, 35112 Växjö, Sweden. E-mail: lena.tibblin@kommun. vaxjo.se

\section{References}

Forsberg, E., \& Starrin, B. (1993). Deinstitutionalisation and the long-term mentally ill: a Swedish case study. European Journal of Public Health, 3, 137-140.

Goffman, E. (1961). Asylums: Essays on the social situation of mental patients and other inmates. New York: Anchor Doubleday.

Grunewald, K. (1997). Psykiska handikapp - möjligheter och rättigheter. Stockholm: Liber. (In Swedish.)

Hansson, J-H. (1993). Organizing normality. Essays on organizing day activities for people with severe mental disturbances. Linköping, Sweden. Institute of Tema Research. Doctoral dissertation.

Middelboe, T. (1995). Community care for the long-term mentally ill: A review of the housing issue. Nordic Journal of Psychiatry, 49, 161-168.

National Board of Health and Welfare. (1999). Välfärd och valfrihet? Slutrapport från utvärderingen av 1995 års psykiatrireform. (In Swedish). Stockholm: Socialstyrelsen 1999:1. Final report of the evaluation of the 1995 Mental Health Care reform. 
National Board of Health and Welfare (Socialstyrelsen). (2003). Housing for persons with psychiatric disabilities. (In Swedish) Boende för personer med psykiska funktionshinder Article no. 2003-13-6

National Board of Health and Welfare (Socialstyrelsen). (2006). Homelessness in Sweden 2005. (In Swedish) Hemlöshet i Sverige 2005. Article no. 2006-131-16.

National Board of Health and Welfare (Socialstyrelsen). (2006). Prevalence of functional impairments in Sweden. Article no. 2006-114-17

Scull, A. (1984). Decarceration. Cambridge: Polity.

SFS 1993:387. Lag om stöd och service till vissa funktionshinder (In Swedish). Disability Act.

SFS 2001:453. Socialtjänstlag (In Swedish). Social Services Act.

SOU. (1992). Välfärd och valfrihet - service, stöd och vård för psykiskt sjuka. (In Swedish). Stockholm: Socialdepartementet 1992:73. Ministry of Health and Social Work. Report of the parliamentary commission, the Committee on Psychiatric care. 